\title{
ENSURING THE RELIABILITY OF TRANSPORT
}

\author{
Gumeni Maria, \\ PhD-student, Technical University of Moldova, Doctoral School - Mechanical and Civil Engineering, \\ Engineering and production management (in the transport branch), Chishinau, Moldova \\ DOI: https://doi.org/10.31435/rsglobal_conf/28022021/7430
}

\begin{abstract}
Road safety is becoming the number one issue. Reliability - a branch of science that studies the general measures to be considered when designing, manufacturing and operating technical systems, in order to ensure maximum efficiency in their use. The car is dependent on the environment, on the processes that influence the triggering of its basic characteristics, during operation. An operation strategy is a set of rules that ensure the specified control of the corresponding operation process. Commercial operations governs the intended use of vehicles. All strategies are closely related to it. Thus, the automobile transport system has the features inherent in complex technical systems: the presence of a single goal, controllability, the interconnection of elements, a hierarchical structure. The system of technical operation of vehicles is a set of vehicles, traffic control devices, drivers, regulations and norms that determine the selection and maintenance of the most advantageous modes of operation of vehicle units, as well as the maintenance and restoration of the lost performance of vehicles in the process of performing transport work. The reliability of the car is the ability of the car to perform the specified functions, keeping the values of the established performance indicators within the limits corresponding to the specified modes and conditions of use, maintenance, repair, storage and transportation.
\end{abstract}

Keywords. design, durability, influence, operation, quality, reliability, road safety.

Introduction. Car transport plays a main role in the country's transport complex, regularly serving enterprises with different forms of ownership, as well as the country's population. More than $80 \%$ of goods are transported by car each year, and around $75 \%$ of passengers travel using public transport.

At the same time, road transport is the main consumer of resources:

- $66 \%$ of petroleum fuels,

- $70 \%$ of human resources,

- and about half of all investments.

The car is operated in a variety of conditions and is a complex system, a set of operating elements - assembly units and parts that ensure the performance of its functions.

By road transport is meant any transport operation carried out by road vehicles for the movement of goods or persons even if the road vehicle is, in a certain part of the road, in turn transported by another means of transport (railway wagon).

Reliability (STAS 8174/77) [6] means the ability of a product to perform its required function under given conditions over a given period of time.

Purpose. Increase traffic safety on national roads.

Specific objective. Analysis of road safety at present, highlighting the characteristic aspects of road accidents, the circumstances and dynamics of their occurrence, and identifying the best practices to increase road safety that could be implemented.

The main motivation for the study of the mentioned aspects comes from the desire to give an answer to an always controversial situation that we encounter frequently.

Reliability of means of transport and ensuring it.

Reliability - a branch of science that studies the general measures to be considered when designing, manufacturing and operating technical systems, in order to ensure maximum efficiency in their use [3].

The car is dependent on the environment, on the processes that influence the degradation of its basic characteristics, during operation. These processes are random and, therefore, for the evaluation of vehicle reliability, methods are used, such as - probability theory and mathematical statistics. Reducing the reliability of vehicles leads to overheads for their repair and time spent for zero travel, at the time of non-operation.

The most complete and objective, following an experimental test, to assess the influence of all conditions and tasks performed, can determine various features of reliability - complete and objective. For this, the following sources of information are used. Fig.1 [2]: 


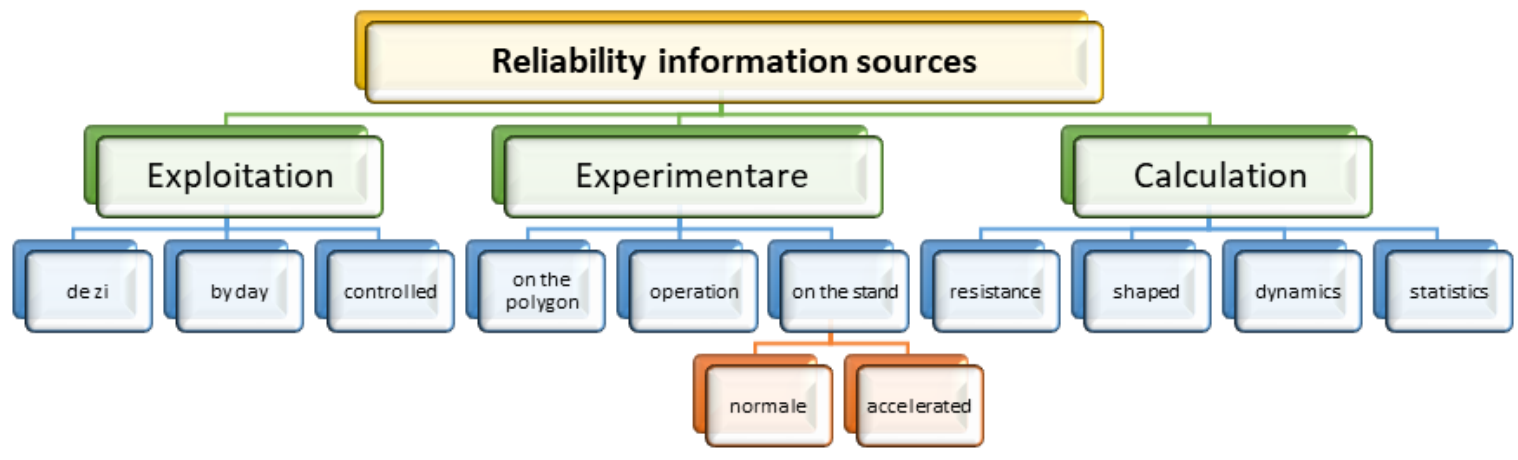

Fig. 1. Sources of information

Reliability, as a complex indicator, is determined by: safety, maintainability, durability and depends on: Fig.2

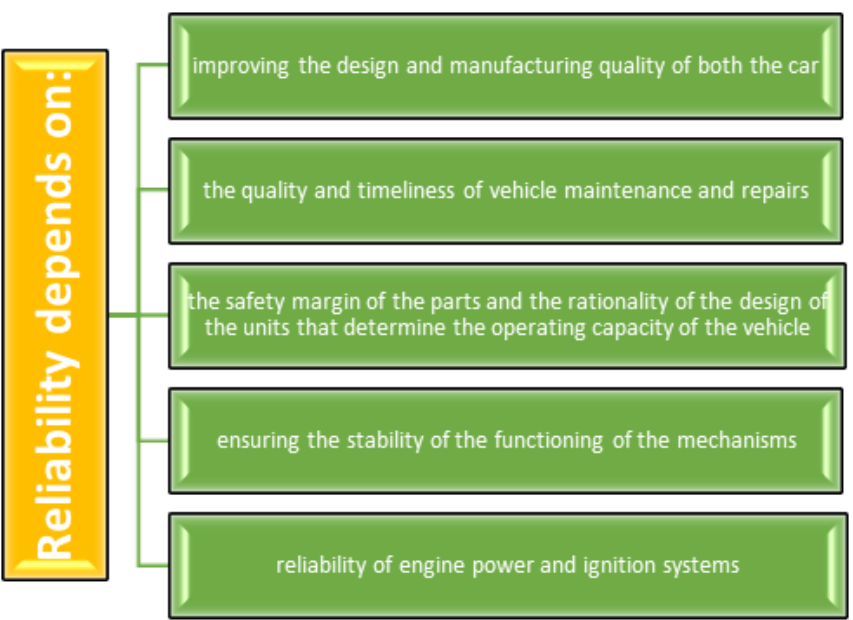

Fig. 2. Ensuring the reliability of means of transport

The extensive use of the "individual" capabilities of various vehicle mechanisms and systems will be allowed through the provision of technical maintenance and repair of cars.

The problem of reliability of mechanisms is in the first place in any industry, because it is necessary to operate the mechanisms with minimal costs. In addition, the importance of the problem lies in the mass production. The reliability of a car is characterized by a complex of qualities, Fig. 3:

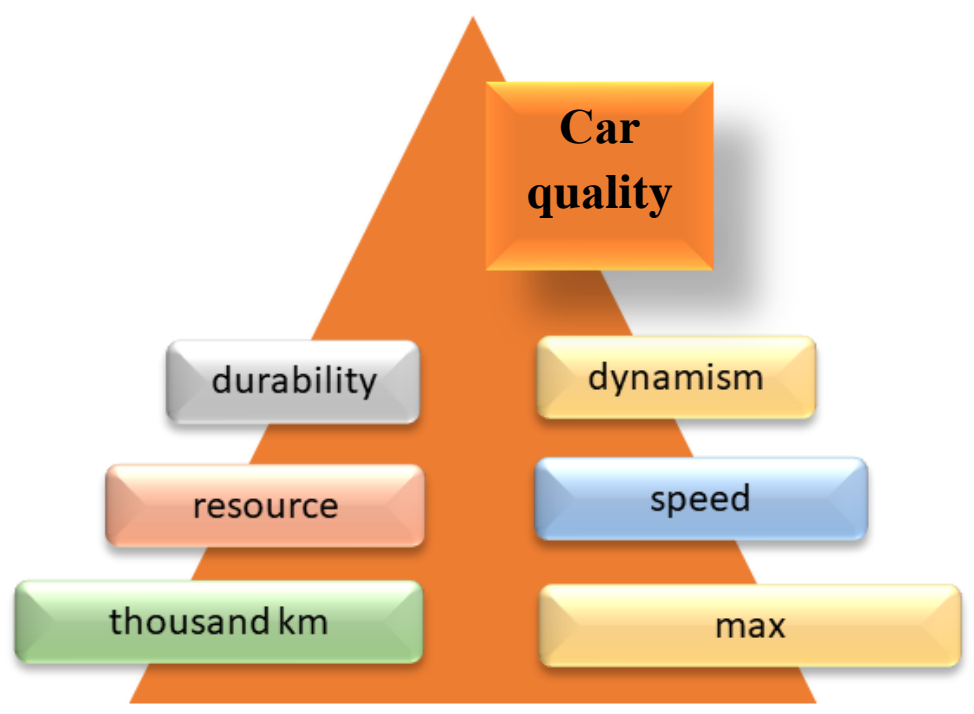

Fig. 3. The matrix of the concept of "vehicle reliability" 
The quality of the products is understood as the totality of product properties that determine its suitability to meet certain needs in accordance with its intended purpose. The totality of product quality properties is assessed by quality indicators. They are divided into indicators of purpose, reliability, manufacturability, transportability, standardization and unification, safety, ergonomic, environmental, aesthetic and patent law. Thus, reliability is one of the main indicators of product quality. There can be no high quality products without high reliability.

\section{The impact of the technical condition of vehicles on road safety.}

The improvement of the roads, the diversity of the car models and the gradual adaptation of the human body, lead to the increase of the extraordinary speeds in circulation. The development of vehicle designs only confirms this growth. In the twentieth century, the speed of the car is increasing, from $30-40 \mathrm{~km} / \mathrm{h}$ to $120-200 \mathrm{~km} / \mathrm{h}$. Race cars became even faster, increasing the speed from 100 $\mathrm{km} / \mathrm{h}$ to $300 \mathrm{~km} / \mathrm{h}$. There are also speed records, with speeds reaching over $1000 \mathrm{~km} / \mathrm{h}$. The speed of intercity buses becomes practically the same as that of cars.

Also, taking into account the safety requirements, the speed allowed in the localities has tripled. The weight of the vehicle has a significant impact on its efficiency in operation. [2] The weight of the car also has a great influence on its cost. The higher the production of a car model (in series), the lower the need for design and research, which reduces its cost. Reducing the weight of the car essentially leads to economy and increased speed. In turn, increasing speed requires more efficient braking system, wheel stability, maneuverability, post-accident and environmental safety. Changing the design of the vehicle requires us to: new driving methods, in various conditions, quality roads and traffic management, the establishment of new rules and even a new organization of their maintenance.

The operating conditions under which cars are used affect the operating modes of units and parts, accelerating or slowing down the change in the parameters of their technical condition, Fig.4:

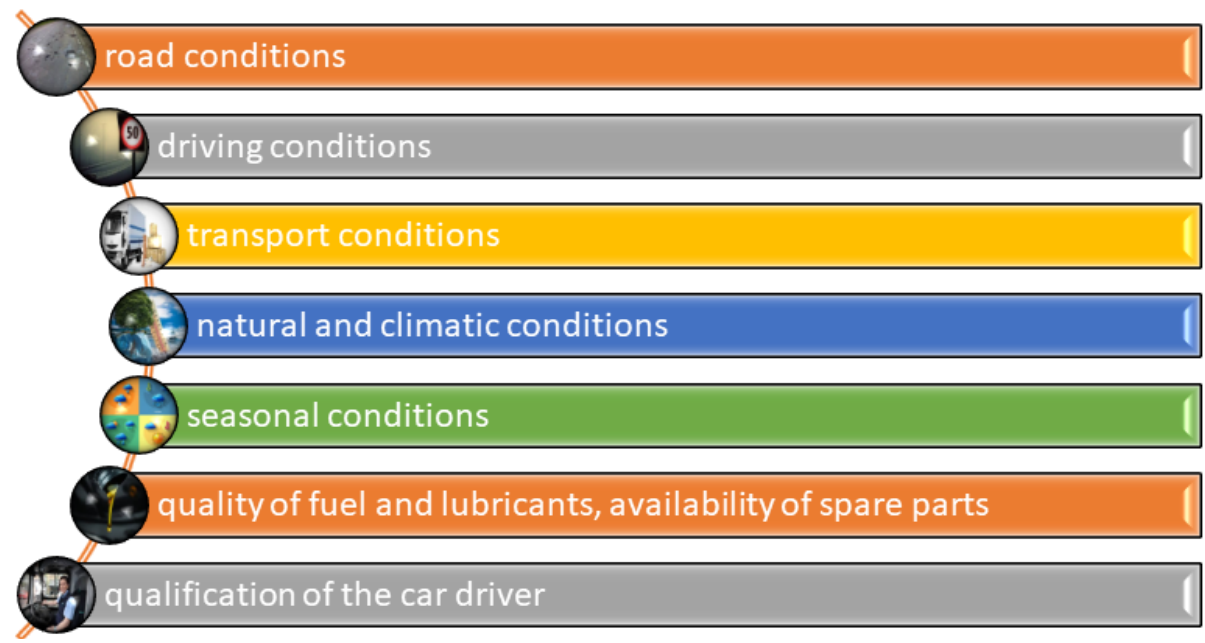

Fig. 4. Influence of operating conditions on changes in the technical condition of vehicles

$>$ road conditions determine the mode of operation of the car and are characterized by the technical category of the road, the type and quality of the road surface, the resistance to the movement of the car, the width of the carriageway, the slopes of the road, the radius of curvature;

$>$ driving conditions are characterized by the influence of external factors on the operating mode of the vehicle and its units;

$>$ transport conditions are characterized by the length of the loaded ride, the coefficients of using the mileage and carrying capacity, the type of cargo;

natural and climatic conditions are characterized by ambient temperature, humidity, wind load, level of solar radiation;

$>$ seasonal conditions, with more than $60 \%$ of all car failures and malfunctions occurring in the spring-autumn period of operation.

At the current stage, the car rarely refuses the driver to fulfill orders, thus reaching the level of excellence. In turn, man, although he developed physically and spiritually, practically did not change his speed of reaction. Being in his youth, the driver is the owner of the fastest reaction, at the same time he is subject to the enthusiasm of competition, eager for accelerated speed. Passing through the 
middle age - the reaction slows down. But, being at any age, the driver is influenced by: the technical conditions of the car, weather conditions, dexterity in driving, psychophysiological condition, consumption of food and drugs, not to mention alcohol. Hence, more than half of all road accidents are caused by the human factor,[7] ie the fault of the driver.

Road safety is becoming the number one issue. Cars were created for the benefit and joy of the people, but their development was so rapid that it came into conflict with the development of localities and roads, with the psychophysiological capabilities of people, with the necessary fuel and resources. Traffic safety depends on many factors. The driver influences the increase of road safety through the way and style of driving, which is very significant. While all other factors directly or indirectly influence its circulation. Fig. 5.

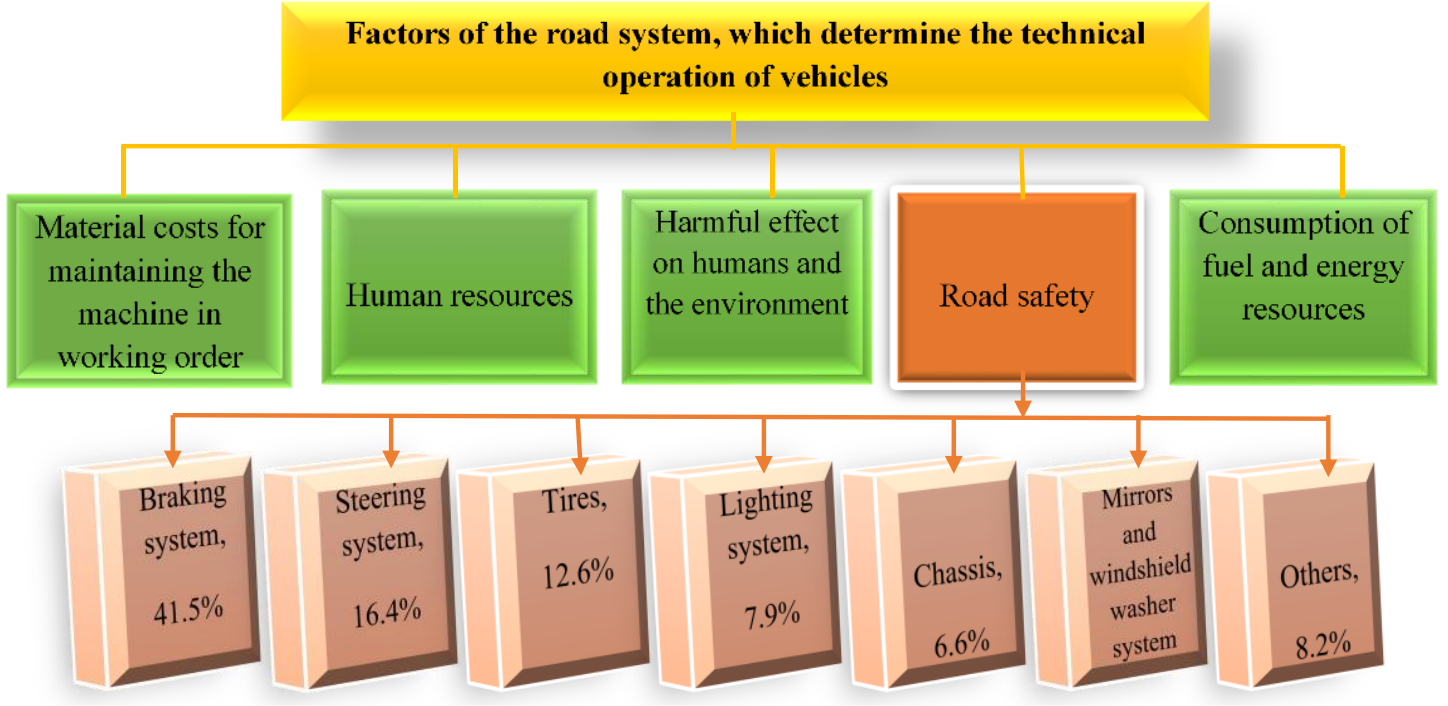

Fig. 5. The technical operation of the vehicles determines the following factors of the transport process

Increasing the operational reliability of vehicles and reducing their maintenance costs is the important problem facing road transport. The solution to this problem is offered by the automotive industry by producing cars with high reliability (maintainability), on the one hand. On the other hand: Fig.6, Fig.7.

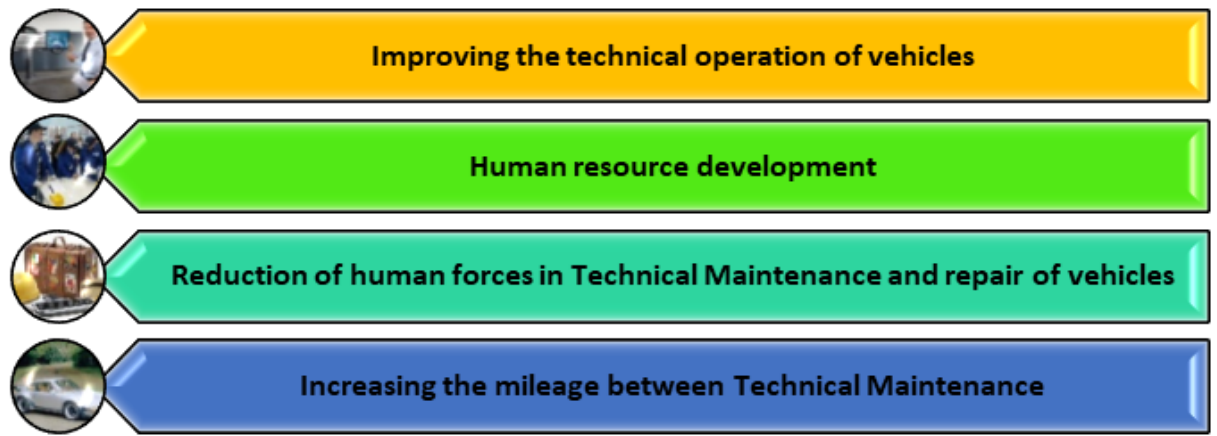

Fig. 6. Increasing the operational reliability of vehicles and reducing their maintenance costs

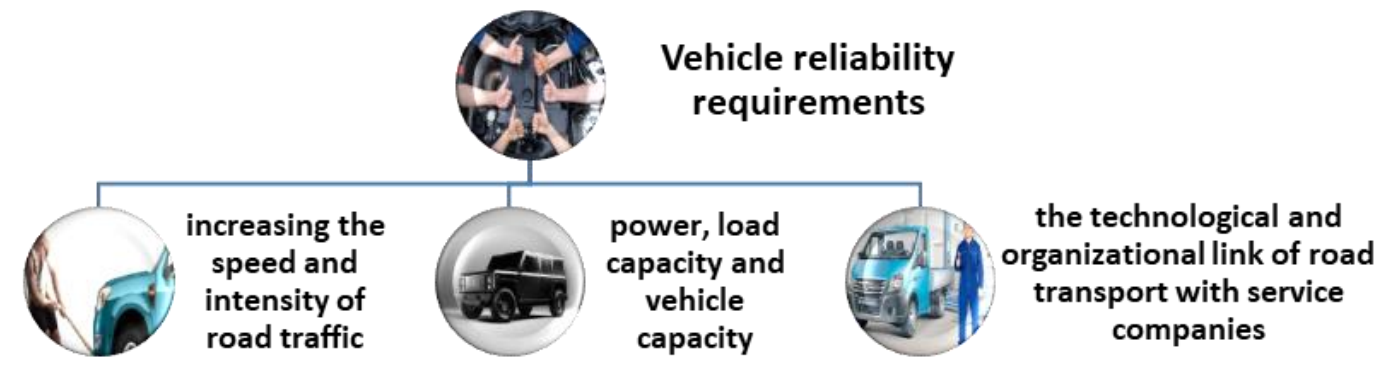

Fig. 7. Ways to streamline vehicle reliability requirements 
The reliability problem is addressed in four main stages:

$>$ determination of the initial requirements for the quality of the new model, taking into account the level of modern technology, existing analogues, market conditions and consumer interests; road tests;

$>$ design, i.e. development of design documentation, implementation of complex bench and

$>$ production;

$>$ work with consumers (collection of information about all failures and malfunctions arising during operation, simplification and reduction of labor intensity of maintenance and repair work, provision of spare parts).

Conclusions. When designing cars, the rule must be observed: the less the expected durability of a particular interface part, the more maintainability the car structure must have. Therefore, the reliability of a car is not only a technical category, but also an economic one. It should reflect the costs of socially necessary labor to create a car and maintain it in working condition during operation. Reliability depends primarily on the level of technical equipment of the manufacturing plant, factories - suppliers of raw materials, the quality of materials, semi-finished products and finished parts. The solution of complex problems of reliability of modern cars is impossible without a deep theoretical study of the physical and chemical processes that cause wear and tear of parts, and the development on this basis of appropriate practical recommendations for the design, production and operation of cars.

The subject described helps us to understand the causes of the decrease in vehicle quality. The deterioration and decrease of the efficiency of the use of vehicles, leads to the creation of certain preconditions for the occurrence of road accidents.

\section{REFERENCES}

1. Loi, V.N., Goronovschii, A.R., Mohov, S.P., Korobkin, V.A., Obespecenie nadejnosti mașin $i$ oborudovania [Ensuring the reliability of machines and equipment]. Belarusian State Technological University, 2010, ISBN 978-985-530-043-5

2. Rusu, V., ALCAZ, T., Oprea, A., Straistrai, C., "Managementul transporturilor" [Transport management]. Chișinău: U.T.M. 2007

3. Retrieved from https://studizba.com/lectures/129-inzhenerija/2054-tehnicheskoe-obsluzhivanie-i-remonttransportnyj-sredstv/39983-5-obespechenie-nadezhnosti-avtotransportnyh-sredstv-v-uslovijahjekspluatacii.html

4. Matskerle, Iu., Modern economical car. In: Mechanical engineering, 1987. - 320: pp. 79 - 94

5. DEX [online]. [accesat 10.01.2021]. Retrieved from https://dexonline.ro/definitie/fiabilitate

6. Fiabilitate, [online]. [accesat 10.01.2021]. Retrieved from https://biblioteca.regielive.ro/cursuri/mecanica/fiabilitatemanagement-119597.pdf

7. Directive (EU) 2018/645 of the European Parliament and of the Council of 18 April 2018 amending Directive 2003/59 / EC on the initial qualification and periodic training of drivers of certain road vehicles intended for the carriage of goods or passengers, such as and Directive 2006/126 / EC on driving licenses In: Jurnalul Oficial al Uniunii Europene [online]. 28.01.2021 Retrieved from https://eurlex.europa.eu/legal-content/RO/TXT/PDF/?uri=CELEX:32018L0645\&from=EN 